\title{
Pathos e cuidado: Dorothy Mae Stang e o cuidado como afetação
}

\section{Pathos and Care: Irmã Dorothy Mae Stang and care as affectation}

\author{
Abdruschin Schaeffer Rocha ${ }^{1}$ \\ Claudete Beise Ulrich ${ }^{2}$
}

\begin{abstract}
RESUMO
O presente texto reflete sobre a relação entre pathos e cuidado. Partindo do conceito de cuidado como modo-de-ser, procura superar a mera ação de cuidar, apontando para a possibilidade de um cuidado como afetação. O conceito de pathos evoca um suportar, um sofrer, ser tocado, ou seja, uma instância em que nunca se está no controle. Nesse sentido, parte do pressuposto de que essa instância também pode ter sentido terapêutico, na medida em que as próprias feridas do cuidador e sua participação nas feridas de outrem se transformam em fonte de cuidado. Nesses termos, apresenta-se uma breve biografia da Irmã Dorothy Mae Stang, uma freira americana, naturalizada brasileira que trabalhou entre os mais pobres na floresta Amazônia. Reflete-se como a sua ação pastoral e missionária foi afetada pela vida dos mais pobres, e pela exploração da floresta, sendo assassinada pelas causas que defendia. A sua história de vida continua afetando a todos e todas que buscam relações mais amorosas e solidárias entre as pessoas e estas com a terra e a floresta. A morte de Dorothy nos toca, denunciando a comercialização da floresta amazônica e nos convoca para o cuidado integral com toda a criação.
\end{abstract}

1 Professor na graduação em Teologia e no Programa de Pós-graduação em Ciências das Religiões da Faculdade Unida. Doutor em Teologia pela PUC-Rio.

2 Professora da Faculdade Unida na graduação em Teologia e na pós-graduação em Ciências das Religiões. Doutora em Teologia pelas Faculdades EST, pós-doutorado em História pela UFSC e pós-doutoranda em Educação pela UFES. 


\title{
PALAVRAS-CHAVE
}

Pathos. Cuidado. Irmã Dorothy Mae Stang. Afetação.

\begin{abstract}
This article reflects on the relationship between pathos and care. Starting from the concept of care as way-of-being, it seeks to overcome the mere caring action, pointing to the possibility of care as affectation. The concept of pathos evokes to bear, to suffer, to be touched, that is, an instance where one is never in control. In this sense, the text assumes that this instance also has therapeutic meaning, since the caregiver's own wounds and their participation in the wounds of others becomes a source of care. In these terms, is presented the biography of Sister Dorothy Mae Stang, an American-born nun, naturalized Brazilian. She worked among the poor people in the Amazon rainforest and it's considered how her pastoral and missionary activity was affected by the lives of the poorest and by the forest's exploitation. Due to the causes she defended throughout her life she was murdered in 2005 . Her life story continues affecting everyone who seeks for more loving and solidarity relationships between people and these with the land and the forest. Dorothy's death touches us, denouncing the Amazon rainforest commercialization and calls us to full-time care with all the creation.
\end{abstract}

\section{KEYWORDS}

Pathos. Care. Sister Dorothy Mae Stang. Affectation.

\section{Introdução}

Uma abordagem é recorrente quando se considera a literatura teológica a respeito do cuidado: normalmente parte-se do pressuposto de que o conceito já está definitivamente estabelecido. $\mathrm{O}$ fato de ter se transformado numa espécie de koiné teológica faz com que a preocupação se concentre no cuidado de (de crianças em situação de risco; de mulheres vítimas da violência; de refugiados etc.), ignorando o que significa efetivamente o cuidar. Ou seja, aplica-se o conceito aos vários grupos humanos vulnerabilizados, supostamente já delimitando o campo de ação do 
cuidado, mas não se discute o cuidado propriamente dito e suas possibilidades. Também na Teologia é possível incorrer-se no problema que se tornou uma das principais preocupações da Filosofia ao longo da história: a banalização do mundo. Frequentemente nos utilizamos de conceitos que parecem já garimpados e resolvidos e perdemos de vista aquela simplicidade e estranhamento que nos possibilita sempre uma vez mais perguntar pelo sentido daquilo que já se tornou da ordem do familiar ${ }^{3}$.

Esse "lugar comum" no trato com o conceito de cuidado acabou por reduzi-lo à simples ação de cuidar. É claro que se pode pensar o cuidado também nesses termos. Mas, a pergunta que se coloca aqui é: como se poderia pensar o cuidado de modo que extrapole a mera ação? Buscando responder a essa pergunta, o presente artigo se divide em duas partes: a primeira pretende expor a insuficiência de um conceito de cuidado que se restrinja à mera ação de cuidar, e sugerir que também seja visto na perspectiva da afetação (pathos); a segunda parte procura apresentar uma breve biografia de Dorothy Stang, e sugerir sua história como fonte de um cuidado que se caracteriza pela afetação.

\section{O cuidado como pathos}

Assumir o pressuposto de que a compreensão do conceito de cuidado visto exclusivamente como ação de cuidar é reducionista, implica em se apresentar sua fragilidade. Além disso, implica também na tarefa de mostrar qual a alternativa que se abre. Esses são os objetivos que norteiam a primeira parte deste artigo.

\subsection{Cuidado como ação $X$ cuidado como modo-de-ser}

Ao comentar o texto de Mateus 16,25-26: "Pois quem quiser salvar a sua vida, a perderá, mas quem perder a sua vida por minha causa, a encontrará" (NVI), Paul Ricoeur propõe uma análise "orientada em

3 VELHO, Gilberto. Observando o familiar. In: NUNES, Edson de Oliveira (Org.). A aventura sociológica: objetividade, paixão, improviso e método na pesquisa social. Rio de Janeiro: Zahar, 1978, p. 39. 
um sentido sapiencial", uma abordagem na qual se isola o versículo de seu contexto cristológico e o aproxima da sabedoria do antigo Oriente Próximo ou mesmo da literatura proverbial universal. Referindo-se ao versículo 26, por exemplo, Ricoeur afirma que "ganhar o mundo", num primeiro momento, significa adquirir bens materiais e poder, postura que se assemelha à divisa da Modernidade anunciada por Descartes, materializada na sedução humana de tornar-se "senhor e proprietário da natureza". Mas, há uma vontade de poder muito mais sutil, que não concerne à posse e ao poder, mas, ao conhecimento. Há uma vontade de poder provocada pela própria força das ideias e também do conhecimento objetivo. Trata-se de uma elevação da natureza que pressupõe o sujeito como portador de conhecimento e, enquanto tal, dominador do mundo dos objetos materiais, dos seres vivos e até das forças sociais em seu aspecto supra individual. Ricoeur indaga: aonde chegaremos, caso se considere que exista uma forma sutil de vontade de poder que se dissimula na forma mais sincera de humildade, que é o amor à verdade?

Minha própria sugestão é que não somente o conhecimento profano está questionado, mas também - e talvez ainda mais - o conhecimento religioso. Se a cristandade buscou tão obstinadamente elaborar provas rigorosas da existência de Deus, não seria por buscar em Deus a garantia suprema em que fundar nossa aspiração de dominar o mundo, um domínio baseado no conhecimento apoiado pela garantia de provas científicas? O sumo do domínio do conhecimento pode bem ser a vontade de incluir Deus no nosso empreendimento de domínio intelectual, pedindo a Deus que garantisse nossa busca obstinada de garantia ${ }^{4}$.

Em seu esforço por uma leitura do texto num sentido sapiencial, aproximando-o da cultura moderna, Ricoeur conclui afirmando que "Tomar uma cruz, é renunciar à representação de Deus como o lugar do conhecimento absoluto, como a garantia de todo o meu conhecimento" ". Não se pode ser simplista ao afirmar que todos os problemas contemporâneos

${ }^{4}$ RICOEUR, Paul. A hermenêutica bíblica. Tradução de Paulo Meneses. Apresentação de François-Xavier Amherdt. São Paulo: Edições Loyola, 2006, p. 235.

5 RICOEUR, 2006, p. 238. 
relativos à compreensão de cuidado sejam decorrentes de uma herança legada pela Modernidade. Mas, por outro lado, também não se pode ignorar o quanto esse projeto moderno, fundado na autonomia, liberdade e racionalidade, empoderou o ser humano, inflacionando tudo o que diz respeito a seu protagonismo no mundo.

A Modernidade proporcionou uma emancipação do mundo não para o seu efetivo cuidado, mas para a sua completa dominação. A separação entre sujeito e objeto instaura uma relação cognoscitiva com o mundo e com os outros, em que a postura do sujeito frente ao objeto caracterizase pela força da ação. Caso aceitemos isso com razoabilidade, podemos aqui partir do pressuposto de que o sujeito moderno é forte, dono de seu destino e senhor da natureza. Nesse sentido, a força do sujeito moderno, tanto presente no ideal de progresso, na violência materializada em projetos colonialistas ou mesmo dissimulada na literatura contemporânea de autoajuda, sem dúvida tem o poder de restringir o conceito de cuidado e consequentemente as várias possibilidades que daí decorrem. De modo geral, pode-se dizer que esse é um "lugar" a partir de onde o conceito de cuidado como ação de cuidar pode ser construído e, consequentemente, a matriz sobre a qual se pode sustentar as formulações teológicas contemporâneas a respeito do cuidado. Talvez esse cenário explique, em parte, porque o limite que demarca a distinção entre o cuidado e a dominação é extremamente tênue.

Partimos do pressuposto de que o conceito de cuidado como ação de cuidar é insuficiente para uma compreensão teológica que dê conta das demandas que surgem do fato de vivermos uma crise civilizacional marcada pela noção de descuido e descaso, virtualmente capazes de comprometer a construção da identidade humana, conforme afirma Leonardo Boff ${ }^{6}$. Mas, quais os problemas de um conceito que se estabeleça exclusivamente nesses termos?

Além do fato de favorecer a relação de dominação pelos motivos já expostos, pensar o cuidado apenas em termos de ação desconsidera por completo o fato de que existem ações estratégicas, na acepção de Habermas, que podem mascarar o cuidado. Uma das dimensões da

${ }^{6}$ Cf. BOFF, Leonardo. Saber cuidar: ética do humano, compaixão pela terra. $12^{\mathrm{a}}$ ed. Petrópolis: Vozes, 1999, p. 18. 
racionalidade da ação, na perspectiva do filósofo alemão, é a "dimensão estratégica", racionalidade essa que desconsidera a importância da validade dos meios e fins desejados. Nesse sentido, a racionalidade estratégica indica aquelas ações que escondem os verdadeiros interesses. Habermas enuncia o seu conceito de ação estratégica (ou teleológica) da seguinte maneira:

O conceito de ação teleológica ocupa desde Aristóteles o centro da teoria filosófica da ação [...] O ator realiza um fim ou faz que se produza o estado de coisas desejado elegendo numa dada situação os meios mais congruentes e aplicando-os de maneira adequada. $\mathrm{O}$ conceito central é o de uma decisão entre alternativas de ação, com vistas à realização de um propósito, dirigida por máximas e apoiada numa interpretação da situação (tradução nossa) ${ }^{7}$.

Ações cuidadosas podem ser empreendidas por pessoas ou instituições, mas, exclusivamente por razões egoístas, tornando-se paulatinamente reféns dos fins desejados. Embora os fins sejam importantes em algum sentido, o cuidado não pode ser reduzido a ações que se determinam fundamentalmente por eles. No Brasil, por exemplo, fama e fortuna - que em geral resultam de razões egoístas - são fins que normalmente estão soterrados e escondidos em camadas de ações cuidadosas por nossos políticos. Tais ações são misericordiosas apenas na aparência, afinal, não são orientadas pelo valor incondicional do outro, mas por aquilo que é possível subtrair dele. Não só são incapazes de traduzir o cuidado em toda a sua nobreza, como também revelam, sempre a seu tempo, o completo descaso pelo humano.

Repercussões práticas de um cuidado que se restringe às ações estratégicas podem se perceber no engano que acaba sendo pulverizado

\footnotetext{
7 "El concepto de acción teleológica ocupa desde Aristóteles el centro de la teoría filosófica de la acción [...] El actor realiza un fin o hace que se produzca el estado de cosas deseado eligiendo en una situación dada los medios más congruentes y aplicándolos de manera adecuada. El concepto central es el de una decisión entre alternativas de acción, enderezada a la realización de un propósito, dirigida por máximas y apoyada en una interpretación de la situación" (HABERMAS, Jürgen. Teoría de la acción comunicativa I: racionalidad de la acción y racionalización social. Madri: Taurus, 1987, p.122.).
} 
culturalmente: se o cuidado se manifesta absolutamente na ação de cuidar, então, certamente prevalece o equívoco de que quando se age cuidadosamente, inevitavelmente o cuidado se manifesta plena e satisfatoriamente. Esse conceito também contribui para a banalização da ideia de cuidado ao se confundir com ações pretensamente caridosas. Além disso, tal reducionismo tem o poder de diminuir o potencial crítico, impedindo que se perceba tratar-se apenas de outra maneira de se legitimar o descuido e descaso para com o outro.

Uma possibilidade que nos permite superar o conceito de cuidado como ação de cuidar é entendê-lo como modo-de-ser, no sentido heideggeriano. Em Ser e Tempo, Heidegger expõe seu conceito de cuidado (Sorge) a partir de contornos ontológicos. Não se refere, portanto, a ações de cuidar, nem mesmo a atitudes de cuidado, mas, designa um modo-de-ser próprio do ser humano que antecede às ações e atitudes. Heidegger busca compreender o ser humano (dasein) como alguém que é lançado no mundo, constituindo-se, nesse sentido, a partir das próprias relações com esse mundo e a partir das relações com os outros dasein. É nesse sentido que o filósofo alemão se aproxima de um conceito de cuidado como modo-de-ser. Reale e Antiseri esclarecem:

[...] assim como o ser-no-mundo do homem se expressa pelo cuidar das coisas, do mesmo modo o seu ser-com-os-outros se expressa pelo cuidar dos outros, coisa que constitui a estrutura basilar de toda possível relação entre os homens. E o cuidar dos outros pode tomar duas direções: na primeira, procura-se subtrair os outros de seus cuidados; na segunda, procura-se ajudá-los a conquistar a liberdade de assumir seus próprios cuidados. No primeiro caso, temos um simples "estar junto" e estamos diante da forma inautêntica de coexistência; no segundo caso, ao contrário, temos autêntico "coexistir".

Como se pode perceber, tanto o ser-no-mundo quanto o ser-com -os-outros se compreendem como lugares constitutivos que se tornam possíveis por meio de uma força fundamental: o cuidado. Enquanto "totalidade originária", o cuidado é modo mais completo no qual se mostra

8 REALE, Giovanni; ANTISERI, Dario. História da filosofia: do romantismo até nossos dias, v. 3. 6. ed. São Paulo: Paulus, 2003, p. 585. 
o ser do ser humano. Mas, o que aqui se reveste de significativa força é o fato de que em seu sentido existencial (como um a priori), embora possa ser encontrado em ações ou atitudes, o cuidado não se identifica com elas, pois as precede. E é por isso que para Heidegger, "teoria' e 'prática' são possibilidades ontológicas de um ente cujo ser deve determinar-se como cura".

\subsection{O cuidado como afetação}

O conceito de cuidado como modo-de-ser, tal como vimos há pouco, fornece-nos a estrutura adequada para se superar o reducionismo que o encerra na ação. Somos convidados, portanto, a pensar o cuidado não apenas por meio da ação - ou mesmo da não ação ${ }^{10}$-, mas, como uma disposição ao sofrimento da ação. Para além da ação e da não ação, falase em uma afetação. Remetemo-nos aqui ao conceito de pathos. Essa palavra, de origem grega, pode ser traduzida por paixão, sofrimento, afecção, afetação etc.; está presente em muitas palavras da Língua Portuguesa, tais como em patologia, simpatia, apatia ou empatia. Pathos diz respeito a um suportar, sofrer, ser tocado. Na filosofia, pode se opor à ação, afinal, trata-se de uma disposição no qual somos sempre passivos. Diferencia-se da ação na medida em que sua força não pode ser prevista, calculada e tampouco controlada, ou seja, refere-se a algo em relação ao qual não se tem controle ${ }^{11}$. Ao contrário da ação, na paixão nunca somos

9 HEIDEGGER, M. Ser e tempo. 2. ed. Petrópolis: Vozes; Bragança Paulista: Editora Universitária São Francisco, 2007, p. 261. Para maiores esclarecimentos sobre o conceito de cuidado em Heidegger, ver ROCHA, Abdruschin Schaeffer. Revelação e vulnerabilidade: caminhos para uma hermenêutica da revelação a partir da presença-ausência. Tese de Doutorado - Departamento de Teologia, Pontifícia Universidade Católica do Rio de Janeiro. Rio de Janeiro, 2015, p. 217-220.

${ }^{10} \mathrm{O}$ conceito de não ação, embora fundamental para corroborar o fato de que o cuidado como ação de cuidar é um conceito extremamente reducionista, não está nos limites deste artigo.

${ }^{11}$ Embora para os gregos o seu contraponto por excelência seja a ação, a razão também pode ser uma instância de esfriamento e esvaziamento do pathos. Em termos culturais, como já vimos, isso pode ser verificado na Modernidade, na medida em que o saber analítico se transforma no meio através do qual se exercerá o controle sobre os mecanismos culturais e de produção e, sobretudo, no interdito dos demais acessos legítimos à realidade que se orientam pelo pathos. E a razão é simples: essa dimensão 
os protagonistas, nunca somos os autores, razão pela qual os filósofos em geral "[...] sempre viram neste estado uma fraqueza e não uma força, uma impotência da alma"12. Além disso, pathos se caracteriza por uma tendência com certa duração, cujos efeitos são intensos e suficientemente poderosos para dominar a vida do espírito.

Nesse sentido, o cuidado como afetação, tal como aqui se sugere, introduz o indivíduo na dimensão do padecimento da ação, instaurando, assim, o "sofrimento" como instância do cuidado. Henri J. M. Nouwen, escrevendo sobre o sentido de ser um ministro no mundo atual, oferecenos um bom exemplo disso ao mostrar a contraposição entre a tradicional imagem do cuidador "distante e contido" e aquela que se caracteriza por oferecer aos irmãos os próprios ferimentos, como fonte libertadora ${ }^{13}$.

Deve-se manter à vista o legado da cultura moderna, instauradora de uma perspectiva na qual o ser humano se distancia da natureza para assim dominá-la. Essa cultura nos sugere dois tipos de relação que podem se dissimular em cuidado e que se contrapõem à perspectiva de afetação: o cuidado de e o cuidado sobre. O ser humano passa a se distanciar de e ao mesmo tempo a estar sobre as coisas, mas não mais com elas. Tal distinção será importante para se compreender o cuidado enquanto pathos. A ideia de um cuidado de e de um cuidado sobre se distancia do que o cuidado com nos propõe. $\mathrm{O}$ cuidado de pressupõe um distanciamento,

afetiva será vista como perturbadora da objetividade científica e dos ideais iluministas. O cogito ergo sum (penso, logo existo) de Descartes reduz a existência ao Logos, ignorando a capacidade humana de ser afetado como um elemento constitutivo. Ou seja, a cultura moderna perde de vista o fato de que "A existência jamais é pura existência; é uma existência sentida e afetada pela alegria ou a tristeza, pela esperança ou pela angústia, pelo empenho, pelo arrependimento, pela bondade" (BOFF, Leonardo. São Francisco de Assis: ternura e vigor. 9. ed. Petrópolis: Vozes, 2002, p. 24.). Mas, em certo sentido, pode-se falar também de uma paixão que paralisa a "ação da razão" sobre a conduta, tal como em Kant: "As paixões dimanam da faculdade de desejar e são tendências que tornam difícil ou impossível qualquer determinação da vontade por princípios" (KANT, Emmanuel apud LALANDE, André. Vocabulário técnico e crítico da Filosofia. $3^{\mathrm{a}}$ ed. São Paulo: Martins Fontes, 1999, p. 783.). Essa constatação reforça nossa tese de que a Modernidade, construída sobre os pilares da liberdade, autonomia e racionalidade, foi em grande medida responsável pela força da ação caracterizada pelo sujeito moderno.

${ }^{12}$ LALANDE, 1999, p. 781.

${ }^{13}$ Cf. NOUWEN, Henri J. M. O sofrimento que cura. $3^{\text {a }}$ ed. São Paulo: Paulinas, 2007. 
semelhante ao que Martin Buber chamou de relação EU-ISSO, uma relação meramente cognoscitiva, na qual está muito clara a distinção entre sujeito e objeto, cabendo a este se submeter àquele $\mathrm{e}^{14}$. $\mathrm{O}$ cuidado sobre, que resulta desse distanciamento, indica um controle e dominação sobre a ordem do mundo, semelhante ao modo como Francis Bacon entendia a relação entre o ser humano e a natureza ("conhecer para dominar") ${ }^{15}$. $\mathrm{O}$ cuidado enquanto afetação, ao contrário, é visto como um cuidado com, próximo o suficiente para se envolver e abrir mão do controle e da dominação, reforçando a dimensão humanizadora da vida.

Inspirados no linguajar na medicina, sugerimos aqui duas metáforas que podem ser interessantes na medida em que nos aproximam do cuidado que se manifesta como pathos: aquilo que poderíamos chamar de "abordagem alopática" e "abordagem homeopática". A primeira concerne a um método terapêutico baseado no princípio da contraposição. Numa perspectiva alopática a cura resulta do uso de remédios que produzem no organismo um efeito contrário ao da doença que está sendo combatida. Na abordagem homeopática, por sua vez, pressupõe-se o princípio da comunhão. Ou seja, utiliza-se de substâncias em pequeniníssimas doses - já que se usadas em quantidade expressiva, produziriam no organismo sintomas semelhantes aos da doença que está sendo combatida - na esperança de que o organismo reaja positivamente e anule os efeitos da doença.

A analogia é sugestiva na medida em que deflagra a seguinte constatação: nossos métodos de cura refletem mais uma abordagem alopática do que homeopática. A abordagem apologética - que historicamente consistiu num jeito específico de lidar com o outro - repercute significativamente em nossa maneira de cuidar no contexto do Cristianismo. Nessa perspectiva, quase sempre se propõe cura aos doentes mediante elementos que se contraponham ao mal que as acomete. Por exemplo: aos tristes e desanimados propõem-se alegria; aos doentes, a saúde; aos quebrantados, a edificação; aos perdidos, a salvação etc. É preciso ainda ressaltar: assim como aqui não se nega o fato de que o cuidado se

\footnotetext{
${ }^{14}$ Cf. BUBER, Martin. Eu e Tu. $8^{\text {a }}$ ed. São Paulo: Centauro, 2001.

${ }^{15}$ Cf. BACON, Francis. Novum Organum. In: EDITORA NOVA CULTURAL. Bacon. São Paulo, 1999.
} 
manifesta, por vezes, em ações de cuidar, é preciso pontuar que o que aqui se nomeia como abordagem alopática não é, necessariamente, um problema. Contudo, deve-se assinalar que numa sociedade altamente secularizada, abrir mão de uma abordagem do tipo "homeopática" faz com que se tenha muito a perder. Tal abordagem se caracteriza por um cuidado que se expressa também por meio da comunhão nos sofrimentos. Ou seja, o cuidado pela afetação

[...] nos levaria a chorar com os que choram (mais do que apenas enxugar suas lágrimas); sofrer com os que sofrem (mais do que eliminar o sofrimento); manifestar ao outro nosso quebrantamento (e não apenas querer edificar); não ocultar nossos extravios (melhor do que apenas ofertarmos a salvação). Isaías 53:5 nos lembra de que "pelas feridas do Messias nós fomos curados". Portanto, ao contrário de um cuidado constituído a partir da "força do cuidador", herança da Modernidade Iluminista, fala-se de um modo-de-ser no qual somos continuamente cuidados pela fragilidade de Cristo. Assim, não é mais a força do sujeito o lugar a partir de onde haurimos a cura, mas sua fundamental fraqueza ${ }^{16}$.

\section{Irmã Dorothy Mae Stang - cuidado como afetação}

Certamente muitas biografias, no passado e no presente, mostram-nos que as feridas também podem ser fonte de cura a uma geração acometida pelo descuido e descaso. No intuito de se sugerir um exemplo de materialização histórica desse cuidado enquanto pathos, neste momento trazemos à memória alguns aspectos da vida da Irmã Dorothy Mae Stang, freira católica, naturalizada brasileira, que entregou a sua vida ao cuidado dos pobres e à floresta amazônica. Stang lutou por um projeto sustentável da terra para o cuidado da floresta e a melhoria de vida dos pobres agricultores, trajetória interrompida por seu assassinato.

${ }^{16}$ ROCHA, 2015, p. $223-224$. 


\subsection{Irmã Dorothy Mae Stang (Dot) $)^{17}$}

Dorothy Mae Stang, mais conhecida como Dot ou Irmã Dorothy, nasceu em Dayton, no estado de Ohio, no dia 7 de junho de 1931. Ela cresceu numa devota família católica irlando-alemã, com seu pai Henry, sua mãe Edna, quatro irmãos e quatro irmãs. Ela era a quarta filha. O pai era um oficial na Base da Força Aérea de Wright-Patterson. Sua mãe trabalhava em casa. Provavelmente, a forte espiritualidade cristã católica vivenciada na família tenha influenciado na decisão profissional/ vocacional de Dot. Ela também estudou na escola das Irmãs de Nossa Senhora de Namur e, nesse período, já alimentava o desejo de se tornar missionária e ir para a China.

Em 1948, Dorothy pediu para ser aceita como noviça das Irmãs de Nossa Senhora de Namur, em Reading, Ohio. Emitiu seus votos perpétuos de pobreza, castidade e obediência, em 1956, recebendo o nome de Irmã Mary Joachim, mas, era chamada de Irmã Dorothy. A congregação religiosa Irmãs de Nossa Senhora de Namur foi fundada em 1804 por Santa Julie Billiart (1751-1816) e Françoise Blin de Bourdon (17561838), na França. As atividades das Irmãs de Nossa Senhora de Namur priorizavam a educação de crianças e o cuidado com os pobres.

Desta forma, de 1951 a 1966, Irmã Dorothy foi professora em escolas da congregação: St. Victor School (Calumet City, Illinois), St. Alexander School (Villa Park, Illinois) e Most Holy Trinity School (Phoenix, Arizona). No Arizona, ela trabalhou com imigrantes. Nesse período, "o Movimento dos Direitos Civis traz à luz o problema do racismo e de todas as injustiças sofridas pelos afro-americanos"18. Nesse período também aconteceu o Concílio Vaticano II (1962-1965), que abriu a Igreja

\footnotetext{
${ }^{17}$ Esta breve biografia está baseada nos livros de LE BRETON, Binka. A Dádiva Maior: a vida e a morte corajosas da Irmã Dorothy Stang. Trad. Renato Rezende. São Paulo: Globo, 2008. SALVOLDI, Valentino. Primeira mártir da criação: Dorothy Stang. Trad. Jaime A. Classen. São Paulo: Paulinas, 2012. BINGEMER, Maria Clara Lucchetti. Mulheres da história recente do Brasil: Dorothy Stang. Disponível em: http://agape.usuarios.rdc.puc-rio.br/amai/mulheresdahistoria1.doc. Acesso em 20 mar. 2019.

${ }^{18}$ SALVOLDI, Valentino. Primeira mártir da criação: Dorothy Stang. Trad. Jaime A. Classen. São Paulo: Paulinas, 2012, p. 24.
} 
Católica ao mundo. Em 1963, o Papa João XXIII lançou um apelo a todas as freiras da América do Norte "para que se dispusessem a dar 10\% do pessoal das diversas congregações ao serviço dos pobres na América do Sul"19.

Esses aspectos históricos e de mudanças teológicas e pastorais fizeram com se concretizasse o sonho de Dorothy em ser missionária. Ela não foi para a China, mas chegou ao Brasil em 1966. Para vir ao Brasil, Irmã Dorothy se inscreveu no Centro de Formação Intercultural e estudou a língua portuguesa, história do Brasil, política, bem como as várias religiões, usos e costumes do povo ${ }^{20}$. É também nesse período que a Teologia da Libertação começa a despontar. Os padres Gustavo Gutiérrez e Jon Sobrino eram docentes no Centro Intercultural. Dorothy conheceu a Teologia da Libertação em seus primórdios. Os teólogos da libertação ${ }^{21}$ denunciavam a exploração dos pobres e apontavam para o grande abismo da desigualdade social na América Latina: pouquíssimas famílias muito ricas e um grande número de miseráveis ${ }^{22}$. Segundo Valentino Salvoldi:

Os teólogos da libertação só podem ser compreendidos no contexto cultural, político e social da América Latina, assim como se pode compreender Irmã Dorotthy à luz dos ensinamentos transmitidos nesse Centro Intercultural, mas, sobretudo, graças à escolha de pôr-se na escola dos povos empobrecidos ${ }^{23}$.

Inspirada pelas mudanças trazidas pelo Vaticano II e pela Teologia da Libertação, em 1966, Irmã Dorothy aceitou o convite e o envio, iniciando seu ministério como missionária no Brasil, na cidade de Coroatá, no Estado do Maranhão. Nesse período, trabalhou especialmente na construção de escolas, cuidado com a saúde e na edificação de Comunidades Eclesiais de Base.

\footnotetext{
${ }_{19}$ SALVOLDI, 2012, p. 25.

${ }^{20}$ SALVOLDI, 2012, p. 25.

${ }^{21}$ BINGEMER, Maria Clara. Teologia latino-americana: raízes e ramos. Rio de Janeiro: Vozes, 2017, p. 43-72.

${ }^{22}$ SALVOLDI, 2012, p. 26

${ }^{23}$ SALVOLDI, 2012, p. 26.
} 
A pequena comunidade das Irmãs de Notre Dame em Coroatá se adapta a viver com base nas necessidades da Comunidade. Cria certa perplexidade ver irmãs à paisana prestarem para todo tipo de trabalho, desde o ensino ao exercício das obras de misericórdia corporal, do comentário da Bíblia à ajuda prestada às mulheres no parto. Mas o que mais desconcerta é ver aquelas irmãs conduzindo um carro. Bem depressa a gente se dá conta, porém, que as mudanças são feitas em benefício dos pobres: o jipe se transforma numa enfermaria ambulante ${ }^{24}$.

Junto com a leitura popular da Bíblia, as irmãs instruem a comunidade sobre os direitos humanos, e é nesse espírito que Irmã Dorothy passa a se dedicar ao trabalho com mulheres prostitutas, ajudando-as a encontrar outras formas de viver dignamente. Em sua constante busca por qualificação, Dorothy fez também curso de enfermagem, a fim de melhor atender aos pobres. As irmãs também assumem um novo jeito de se vestir, à semelhança do povo, e abandonam os antigos costumes ${ }^{25}$ : abriram mão do hábito, usaram saias-calças e eram mulheres que sabiam dirigir $^{26}$. A teologia da libertação também aliviou freiras e padres do peso de ter que assumir sozinhos a tarefa de levar a salvação ao mundo e contribuiu para o envolvimento das pessoas leigas em uma participação ativa na vida da Igreja. Assumir a condição de ser Igreja dos pobres era também aprender a viver e a comer com os pobres ${ }^{27}$. Não se pode esquecer que todo o trabalho das irmãs era realizado no período da ditadura militar $^{28}$. O trabalho foi muito difícil, pois o estado do

Maranhão era (e permanece) um estado feudal, controlado por algumas famílias de proprietários de terra e políticos. Ali a maioria das pessoas era considerada capacitada apenas a lavrar o solo e cuidar do gado e a viver submetida ao patrão, ao padre e ao prefeito. As crianças deviam obedecer aos pais sem questionar, as mulheres a acatar e cuidar de seus homens, e todos deveriam apoiar a hierarquia, que beneficiava apenas o topo ${ }^{29}$.

\footnotetext{
${ }^{24}$ SALVOLDI, 2012, p. 29.

25 LE BRETON, 2008, p. 74.

${ }^{26}$ LE BRETON, 2008, p. 78.

${ }^{27}$ LE BRETON, 2008, p. 82.

${ }^{28}$ LE BRETON, 2008, p. 89.

${ }^{29}$ LE BRETON, 2008, p. 75-76.
} 
As irmãs eram consideradas comunistas, pois começaram a falar de direitos humanos, lutar pelo título da terra e levar educação aos pobres. Havia muita pobreza, mas isso não era o maior desafio. O mais difícil "era o fato de viverem com medo. Temiam os senhores da terra, temiam a polícia, temiam o exército" ${ }^{30}$. Como irmãs estrangeiras, em geral eram vistas com desconfiança. Por sua firmeza e por não demonstrar medo, Irmã Dorothy era fotografada, gravada e ameaçada de prisão ${ }^{31}$. Foi na década de 70 que teve início um projeto de ocupação da Amazônia. No entanto, o modelo escolhido não beneficiava os pobres e nem a floresta, gerando grandes graves conflitos pela titularidade da terra.

Em 1974, as irmãs Dorothy e Becky receberam um chamado ainda mais radical da Diocese de Marabá, no estado do Pará, uma região no meio da floresta amazônica, marcada pela extrema pobreza e abandono. Dorothy tinha uma paixão muito grande pela natureza, provavelmente uma herança de sua família. Numa entrevista para a emissora de televisão Canção Nova, ela disse

O grande amor que nutro pela terra vem da minha família. Eu o devo a eles. Meu pai trabalhou na terra por muitos anos, desde a infância. E ele sempre me ensinou que é preciso lavrar a terra de modo tal que, quando o trabalho estiver terminado, a terra esteja mais rica do que quando se iniciou. A terra é uma criatura viva e nós não podemos tirar a vida dela só para nós mesmos. A terra deve viver sempre. Devemos tratá-la com grande respeito e afeto porque ela é fonte de vida para todo o Povo de Deus. ${ }^{32}$

No entanto, a beleza e o silêncio da floresta são cortados pelo ruído estridente da motosserra. Isto dói demais para as pessoas e as irmãs que estavam lutando pela preservação da floresta.

Provavelmente é exatamente esse contraste que leva a mulher de fé Dorothy a ser ainda mais determinada, a lutar para que não seja anulado tal recanto de paraíso, e para que nele os moradores possam

\footnotetext{
${ }^{30}$ LE BRETON, 2008, p. 90.

${ }^{31}$ LE BRETON, 2008, p. 91

${ }^{32}$ SALVOLDI, 2012, p. 74.
} 
continuar a viver numa pobreza digna. Lutar pela salvaguarda da criação. Lutar para que os pobres não percam a esperança. Lutar pela conversão daqueles latifundiários cegados pela insaciável cobiça de dinheiro e de terra, que cegou os poderosos do Brasil ${ }^{33}$.

O conflito entre os grileiros, madeireiros, latifundiários e os assentados se agrava. Dorothy não deixa de denunciar as injustiças contra a floresta e os/as pobres camponeses, assentados, sem-terra. Dorothy e as irmãs incentivam a criação do Sindicato dos Trabalhadores Rurais e alfabetizam o povo com as novas maneiras de ler a Bíblia. ${ }^{34}$ Em 1975, [...] a

Conferência Nacional dos Bispos estabeleceu a Comissão Pastoral da Terra (CPT), com o objetivo de apoiar as pessoas na luta pela terra.Líderes da Igreja e da comunidade logo compreenderam a necessidade de trabalharem juntos e começaram a associar as comunidades de base com a CPT recém-criada e o movimento educacional ${ }^{35}$.

Não foi fácil unir as pessoas, pois tinham vindo de diferentes partes do país para a Amazônia e o mais difícil foi mudar a mentalidade em relação à forma de cultivar a terra. Buscava-se trabalhar coletivamente a partir do "conceito de agrofloresta, plantando bem no seio da floresta em lugar de abrir clareiras" 36 . Havia muitas perseguições às lideranças (irmãs, padres, assentados/as) que lutavam pela sustentabilidade ambiental e denunciavam as injustiças com os/as assentados/as, a terra e a floresta.

Também o nome de Dorothy aparece na lista dos que devem ser eliminados. E a lista é publicada na imprensa local. O bispo diocesano, Alano, começa a passar da preocupação ao nervosismo em relação a Dorothy que, sentindo faltar a sua confiança, decide mudar de ambiente e ser enviada para a parte mais remota da floresta, onde as injustiças e os riscos são ainda mais numerosos ${ }^{37}$.

\footnotetext{
33 SALVOLDI, 2012, p. 33-34.

${ }^{34}$ LE BRETON, 2008, p. 104-195.

${ }^{35}$ LE BRETON, 2008, p. 105.

${ }^{36}$ LE BRETON, 2008, p. 192.

${ }^{37}$ SALVOLDI, 2012, p. 38.
} 
Em 1982, Irmã Dorothy, com 51 anos, resolve se mudar e vai para Altamira, no rio Xingu, para falar com o Bispo Erwin Kräutler e informá-lo de seu desejo em trabalhar com os mais pobres dos pobres ${ }^{38}$. Inicia novamente seu trabalho de visitar as famílias, convidando a se reunirem nas pequenas comunidades eclesiais de base. Há dificuldades de comunicação e de reunir os migrantes que vêm do Sul, descendentes de italianos e alemães com os habitantes nativos do Norte, que por sua vez, são descendentes de índios, africanos e portugueses. Irmã Dorothy, com seu trabalho missionário e pastoral cuidadoso, através da construção das pequenas comunidades de base consegue juntar as pessoas, elas começam a se conhecer, ler a Bíblia, orar juntas e começam a se ajudar de forma solidária e coletiva ${ }^{39}$.

Dorothy não se conformava com a forma como os pobres tinham que viver. Ela se envolveu com os Projetos de Desenvolvimento Sustentáveis (PDS), sendo esta uma forma modesta do governo fazer uma nova reforma agrária na Transamazônica. Era necessário aprender a viver na Amazônia, de forma sustentável e não destruindo a floresta. Dorothy assumiu integralmente este novo jeito de fazer reforma agrária e foi assassinada em função disso. Ela ensinou as pessoas a amar e respeitar a floresta - não ter medo dela -, e com ela iniciou-se uma fase de formação de professores/as e de técnicos agrícolas. Além disso, novas relações entre homens e mulheres ${ }^{40}$ foram se estabelecendo, de respeito e ajuda mútua. Digno de nota é, também, a mudança radical de Irmã Dorothy em sua forma de viver e trabalhar, experimentada a partir do curso de Teologia da Criação ${ }^{41}$ que realizou na Universidade do Mais Sagrado Nome, na Califórnia, por ocasião do período de descanso em seu país. $\mathrm{O}$ ativismo social que a tinha consumido vai dando lugar a uma religação com

as pessoas, plantas, animais, água, ar e a própria Terra. [...] Por 25 anos, na busca de justiça social, ela trabalhou com os sem-terra para ajudá-los a ganhar o sustento. E por 25 anos o mesmo padrão se repetiu: a floresta fora cortada, a terra, degradada, e as famílias, forçadas

\footnotetext{
${ }^{38}$ LE BRETON, 2008, p. 123.

${ }^{39}$ SALVOLDI, 2012, p. 39.

40 LE BRETON, 2008, p. 152. Com seu trabalho fortaleceu as mulheres e as meninas.

${ }^{41}$ SALVOLDI, 2012, p. 97-139; LE BRETON, 2008, p. 145-154.
} 
a vender e a se mudar. $\mathrm{O}$ jeito antigo não estava funcionando, e uma nova maneira precisava ser descoberta ${ }^{42}$.

A partir daquele curso, a imagem de Deus também é transformada de Deus Pai para Deus Pai/Mãe da justiça, da compaixão e da sabedoria. Tem lugar a descoberta de uma nova espiritualidade, não mais baseada no pecado original, mas, na benção original: Deus criou o universo e viu que isto era bom ${ }^{43}$. Irmã Dorothy "resolveu que quando voltasse ao Brasil trabalharia com as mulheres e os homens para tornar as suas terras mais produtivas, [...] fazendo-as compreender seu papel na criação - quanto mais cuidaria da terra, mais a Terra cuidaria delas"44. "Dorothy extraia a sua força da Bíblia e do Livro de Horas"45.

Desde 1976, ela fez parte da Comissão dos Bispos para a Pastoral da Terra. Em 1992 participou da histórica Conferência das Nações Unidas para o Ambiente e o Desenvolvimento, realizada no Rio de Janeiro. ${ }^{46}$ Numa de suas cartas escreveu: "Devemos ajudar as pessoas a voltar a uma relação com a Mãe Terra que seja terna e gentil. É um dom de Deus viver de modo intenso como partes do nosso universo cósmico" ${ }^{47}$.

Em 1995, Dorotthy lutou para que o pequeno lugarejo Anapu, no Pará se tornasse um município, a fim de que fosse melhor atendido pelo governo. No entanto, os vencedores se colocaram ao lado dos fazendeiros e madeireiros. Mas ela não desistiu, mesmo sendo acusada de dividir as pessoas, chamada de comunista e de distribuir armas aos trabalhadores rurais pobres. O projeto que Irmã Dorothy defendeu junto com irmãs, padres, religiosos e trabalhadores/as rurais são, na verdade, os Projetos de Desenvolvimento Sustentáveis (PDS), que significavam o cuidado da terra de forma responsável. Numa carta ela escreveu:

[...] Sei que querem me matar, mas não vou embora. O meu lugar é aqui com esta gente que é continuamente humilhada por todos os que se acham poderosos.

\footnotetext{
${ }^{42}$ LE BRETON, 2008, p. 145-146.

${ }^{43}$ LE BRETON, 2008, p. 149.

${ }^{44}$ LE BRETON, 2008, p. 152.

${ }^{45}$ LE BRETON, 2008, p. 128.

46 SALVOLDI, 2012, p. 58-63.

${ }^{47}$ SALVOLDI, 2012, p. 57.
} 
Noutra carta:

Sei que a fé sustenta e aprendi que três coisas são difíceis: como mulher, ser levada a sério nas reformas pela terra; permanecer fiel à convicção de que estes pequenos grupos de pobres trabalhadores chegarão um dia a se organizar e levar avante os seus projetos; e ter a coragem de sacrificar a própria vida na luta pelas mudanças ${ }^{48}$.

Enquanto continuam as acusações de latifundiários, grileiros e madeireiros contra Irmã Dorothy, a Organização dos Advogados do Brasil (OAB) para os direitos humanos lhe confere a Medalha Chico Mendes, no ano de 2004. Recebeu também a cidadania honorária do Pará, que ao mesmo tempo a declara a mulher do ano ${ }^{49}$. Todas estas homenagens fizeram aumentar o número de seus inimigos. Em janeiro de 2005, espalhou-se a notícia de que a morte da Irmã Dorothy estava sendo planejada por um grupo de proprietários num hotel em Altamira. No entanto, ela não acreditou que a matariam, pois era uma mulher idosa, com 73 anos. Numa carta ela assim se expressou: Pouco antes de ser assassinada declarou: "Não vou fugir e nem abandonar a luta desses agricultores que estão desprotegidos no meio da floresta. Eles têm o sagrado direito a uma vida melhor numa terra onde possam viver e produzir com dignidade sem devastar" ${ }^{50}$

Não temendo a morte, em fevereiro de 2005 ela viajou com dois trabalhadores rurais, para Esperança, no Pará, para participar de uma reunião do Projeto de Desenvolvimento Sustentável (PDS) ${ }^{51}$.

Propõe-se a fazer mais uma das suas enésimas tentativas para convidar os trabalhadores a não deixar a terra quando recebem pesadas

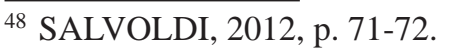

${ }^{49}$ SALVOLDI, 2012, p. 75.

${ }^{50}$ BINGEMER, 2009, p. 1.

${ }^{51}$ PDS (Projeto de Desenvolvimento Sustentável) incentivado desde 1995, pela missionária Irmã Dorothy Mae Stang. "Nele o solo é preservado, sendo utilizado pequena parte do mesmo para a sobrevivência imediata das famílias assentadas com culturas tradicionais. Grande parte é destinada à preservação da natureza. O ganho a médio e longo prazo é tirado das riquezas que as próprias florestas oferecem como a comercialização de óleos de copaíba, andirobas e castanha-do-pará, plantação de cacau, pupunha e pimenta-doreino, criação de peixe, comercialização de polpa de açaî" GUZZO, Maria Rosário Souza; SANTANA, Nivalda Silva de. Irmã Dorothy Stang: a mártir dos PDS. A vida de Dorothy Stang na Amazônia. Anapu, 2009, p. 47. 
ameaças e os latifundiários queimam as suas casas. Abandonar a terra significa dar aos ricos prepotentes mais coragem para continuar os seus trabalhos sujos, aproveitando-se do terror semeado entre o povo pobre ${ }^{52}$.

No entanto, na manhã do dia 12 de fevereiro de 2005, quando se dirigiu à comunidade Esperança, num caminho estreito, no meio da floresta, foi encurralada por dois homens (Raifran e Clodoaldo ${ }^{53}$ ), que barraram a sua passagem. Dorothy não demonstrou medo, os cumprimentou e "começa a discutir os direitos da terra. Convida-os a não semear capim para o gado, porque isso prejudica o ambiente. Fala da necessidade de salvaguardar a floresta e, ao mesmo tempo, afirma que entende a posição deles: são soldados que devem obedecer ordens" ${ }^{54}$.

O amigo Cícero que seguia Irmã Dorothy conseguiu se esconder entre as árvores, sendo a única testemunha deste triste momento. No diálogo com Raifran e Clodoaldo ela mostrou os mapas das terras, apontando que as mesmas pertencem aos assentados. Os homens não queriam saber de conversa e Raifran perguntou se ela tinha uma arma na sacola. Neste momento, de acordo com uma testemunha, Irmã Dorothy tirou a Bíblia e leu as bem-aventuranças e convidou os dois para irem à reunião $0^{55}$.

Com firmeza e coragem, ela se despediu e retomou o seu caminho. Raifran, no entanto, gritou pelas costas que, se não tivesse resolvido o problema dos trabalhadores, não os resolveria mais. Irmã Dorothy ergueu a mão, segurando a Bíblia, como se dissesse adeus.

Raifran atirou. O primeiro tirou atravessou a outra mão e terminou na barriga. Dorothy caiu com o rosto na terra. Recebeu outros tiros de pistola. Tiros simbólicos na cabeça, no coração e no ventre, para eliminar o pensar, o sentir, e o gerar. Porque aquele cérebro, aquele coração e aquele ventre foram uma ameaça para aquele tipo de desenvolvimento difundido no Brasil e especialmente na Amazônia ${ }^{56}$.

\footnotetext{
52 SALVOLDI, 2012, p. 76.

${ }^{53}$ LE BRETON, 2008, p. 233. Ao invés do nome Clodoaldo, a autora coloca o nome Eduardo para o ajudante de Raifran. Ela também escreve Rayfran com y. O presente texto usa o nome Raifran com i.

54 SALVOLDI, 2012, p. 76.

55 SALVOLDI, 2012, p. 76-77.

56 SALVOLDI, 2012, p. 77.
} 
Nada deteve, entretanto, os assassinos "nem a Palavra de Deus deteve o ímpeto assassino das balas fatais" ${ }^{57}$. Mesmo morta ela continua ligada ao seu povo e a floresta que tanto amava. Ela foi sepultada a sombra de uma mangueira

na floresta amazônica, ao lado do seu povo. Aquele povo que agora continua a repetir 'Dorothy vive' cada vez que alguém eleva a voz para dar o seu testemunho. Entre tantas afirmações em sua homenagem, eis a da sua mais querida amiga, Irmã Jo Anne: 'Hoje não sepultaremos Dorothy. Como uma árvore, nós a plantaremos ${ }^{58}$.

Dorothy amava a floresta, a terra, as pessoas e por esta causa foi assassinada. Nem todos aqueles grandes fazendeiros, entretanto, que planejaram a sua morte estão presos ou foram julgados. "O fazendeiro Vitalmiro Moura, o Bida, acusado de ser o mandante do crime, havia sido condenado em um primeiro julgamento a 30 anos de prisão. Num segundo julgamento, contudo, foi absolvido" 59 . Raifran e Clodoaldo foram condenados e estão presos.

\subsection{Dorothy e o cuidado como afetação}

Certamente, a história de vida da Irmã Dorothy é um testemunho do quanto o cuidado pode atingir níveis mais profundos que extrapolam as ações de cuidar. Ela não somente agiu cuidadosamente, mas, definiuse como Cuidado, na medida em que seus vínculos com a terra a redefiniram como pessoa, no sentido heideggeriano de ser-no-mundo. Ela dedicou a sua vida a construir escolas, educar as pessoas e preocupar-se com a saúde. As comunidades eclesiais de base serviram-lhe de ambiente para o diálogo entre a Bíblia e a vida, facultando-lhe a possibilidade de ensinar sobre os Direitos Humanos, dando voz aos pobres trabalhadores rurais. A leitura popular da Bíblia - em que as Escrituras entram

\footnotetext{
57 BINGEMER, 2009, p. 3.

58 SALVOLDI, 2012, p. 79.

${ }^{59}$ BINGEMER, 2009, p. 3.
} 
em parceria com a terra ${ }^{60}$ - enfatizava uma espiritualidade ativa que se misturava com a alfabetização das pessoas. Dorothy também desafiou os grandes projetos de desenvolvimento na Amazônia, apostando no Projeto de Desenvolvimento Sustentável (PDS), a partir do qual somente 20\% de uma grande área seriam plantadas, mantendo-se intacto o resto da floresta. Lutou pelos direitos dos mais vulneráveis, tais como mulheres, jovens e trabalhadores rurais sem-terra, mostrando a estreita relação entre a exploração dos pobres e as questões relativas à floresta e à própria terra, despertando, assim, ódio nos grandes madeireiros e fazendeiros.

A atividade pastoral e missionária de Dorothy buscava a geração de emprego e renda a partir de projetos de reflorestamento em áreas degradadas. Vale ressaltar que para as pessoas de tradição cristã católica o grande pastor é Jesus Cristo, o Deus conosco. Portanto, para Dorothy, fazer um trabalho pastoral significava imitar a Jesus Cristo, não apenas cuidando de ou cuidando sobre, mas, especialmente, cuidando com os mais vulneráveis e pobres, ou seja, participando da comunhão de seus sofrimentos ${ }^{61}$. É por isso que sua proximidade e participação nos sofrimentos dos pobres, da própria terra e da floresta revelam um cuidado que se dava em termos muito mais "homeopáticos" do que "alopáticos". Tal como seu mestre, ela morreu pelas causas com as quais se comprometeu no nível da vida.

A biografia de Dorothy mostra o nível de envolvimento e compromisso com aqueles a quem dedicou inteiramente sua vida. Seu enfrentamento dos muitos poderes, tais como, madeireiros, governo, policia, justiça etc., só foi possível pelo fato de ter sido irremediavelmente

${ }^{60}$ AGORA mais do que nunca: Irmã Dorothy Stang. 14 Fevereiro 2019. Disponível em: http://www.ihu.unisinos.br/78-noticias/586645-agora-mais-do-que-nunca-irmadorothy-stang. Acesso em 30 mar. 2019.

${ }^{61} \mathrm{O}$ trabalho de Dorothy se concentrava na minimização dos conflitos fundiários na região. Atuou ativamente nos movimentos sociais no Pará. Ela amava tanto o Brasil que se naturalizou brasileira. Dentre os muitos grupos com os quais se identificou em sua luta, destacam-se os pobres da Amazônia, representados por migrantes, boiasfrias, lavradores, pessoas totalmente despossuídas de tudo. Seu trabalho lhe rendeu a alcunha de "Anjo da Amazônia". Dorothy e as irmãs que com ela trabalhavam empenharam-se em denunciar a destruição da floresta tropical para a implantação de pasto. Sua entrega à causa e sua perspectiva da relação entre a floresta e o povo levaram-na a concluir que a morte da floresta significava a morte das próprias pessoas. 
afetada pelo sofrimento imposto aos pobres e danados da Amazônia. Suas feridas tornaram-se as feridas dela, sua pobreza tornou-se a pobreza dela. Foi-lhe necessário, também, paciência com os pobres trabalhadores rurais que estavam acostumados com um tipo inadequado de tratamento da terra. Sua participação cada vez mais intensa e mais vinculada ao contexto permitiu-lhe ensinar o cuidado da terra, postura subversiva em relação aos interesses econômicos e ao ímpeto predatório. A postura de Dorothy com relação à floresta partiu do pressuposto de que há uma maneira de servir-se da natureza respeitando-lhe sua vocação própria. Ou seja, há um certo "pudor" próprio da floresta que deve ser respeitado, tal qual nos mostra a techné grega ${ }^{62}$, e cuidar nesses termos exige uma participação que supera o mero estar sobre (dominação) e o mero cuidar de (relação cognoscitiva).

Se por um lado, Irmã Dorothy foi profundamente afetada tanto pelo Evangelho de Jesus Cristo quanto pelo sofrimento que se abateu sobre aqueles a quem cuidava, a ponto de ser assassinada, por outro, seu cuidado e clamor, qual caixa de ressonância, continua a nos afetar. Como lembra Bingemer: "Seu martírio, no entanto, é força viva que, como grão de trigo enterrado e morto, dará abundantes e fecundos frutos em prol de maior justiça para o povo brasileiro" 63 .

O Brasil dificilmente honra adequadamente suas vítimas e mártires. Dificilmente se percebe a força dessa memória na construção do ethos brasileiro. Ao contrário, temos a discutível capacidade de reescrever a história e calar as vozes daqueles que clamam desde a terra (cf. Gn 4,10). Há vozes que clamam desde a floresta; há vozes que clamam no deserto; há vozes que clamam nas favelas; há vozes que clamam no seio de lares

\footnotetext{
${ }^{62}$ A techné grega implica em um tipo de manipulação das coisas do mundo que respeita a vocação natural de cada ente. Essa recriação (poiésis) do mundo que se submete à sua própria vocação indica certo protagonismo do mundo em seu desabrochar ( $p h y$ sis) e a disposição humana que assume a fragilidade própria de sua condição "pastoral". É nesses termos que Heidegger afirmará que o ser humano é pastor do ser: "El hombre no es el señor de lo ente. El hombre es el pastor del ser. En este "menos" el hombre no sólo no pierde nada, sino que gana, puesto que llega a la verdad del ser. Gana la esencial pobreza del pastor, cuya dignidad consiste en ser llamado por el propio ser para la guarda de su verdad" (HEIDEGGER, Martin. Carta sobre el humanismo. Madrid: Alianza Editorial, 2006. p. 57).

${ }^{63}$ BINGEMER, 2009, p. 3.
} 
onde impera a violência; há vozes que clamam nas ruas; há muitas vozes, mas, sempre se tem a opção de calá-las ou, ao contrário, deixá-las ecoar. Dorothy é a lembrança de que o martírio e as vítimas são vozes que devem ser amplificadas desde os seus lugares e a Igreja de Jesus Cristo, por sua vez, a caixa de ressonância dessas feridas que podem curar gerações subsequentes. Urge a necessidade de uma nova perspectiva eucarística, que se construa à revelia dos lugares santos e dos rituais desencarnados, afinal, Jesus Cristo não deveria ser apenas rememorado estética e liturgicamente, mas, replicado na anamnese das vítimas que eucaristicamente emprestam suas feridas para a cura do mundo. Mas, é preciso resgatar o pathos que deriva de corpos transgredidos e dos loci profanados. Essa memória afeta as comunidades cristãs na medida em que se deixam interpelar e desafiar à contínua luta pelos direitos dos fracos e oprimidos.

Na floresta Irmã Dorothy foi sepultada como guardiã da criação. Sua dor e morte se misturam com a morte da floresta, da terra e dos trabalhadores rurais, e nos desafiam em nossa forma de cuidar da "Casa", para além de nossa própria geração. Embora não suficientemente, ecos de Dorothy se fizeram sentir depois de sua morte, afinal, seu sofrimento, dor e martírio provocaram reflexões e revisões quanto ao valor da floresta, da vida dos pobres e da terra, instâncias que, segundo ela, estavam intimamente conectadas. Dorothy Mae Stang - a mártir da floresta cuja empatia se dava até mesmo com os seus algozes - encarnou um cuidado que continua nos afetando, desafiando e provocando-nos ao cuidado de toda a criação.

Desde essa perspectiva, “o significado do legado da irmã Dorothy é para toda a Amazônia um raio de esperança, é para todos os povos uma certeza de que só na resistência, na articulação e organização que vamos preservar o que ainda resta de vida aqui na Amazônia, povos, floresta, rios, a biodiversidade", [... $]^{64}$. A Irmã Dorothy afirmou, certa vez, que "apenas uma profunda mudança em nosso modo de vida - nossos valores

\footnotetext{
${ }^{64}$ GARCIA, Leoni Alves. Dorothy Stang e Ezequiel Ramim, testemunhas de uma vida doada pela Amazônia.23 de julho de 2018. Disponível em: https://cebsdobrasil.com. br/2018/07/23/dorothy-stang-e-ezequiel-ramim-testemunhas-de-uma-vida-doada -pela-amazonia1/. Acesso em 27 mar. 2019.
} 
e atitudes - pode trazer uma nova vida ao nosso mundo" 65 . Inspiradas/os em Dorothy, somos convidados ao cuidado na perspectiva da afetação, a fim de que seja possível mudar as relações de opressão e exploração, na construção de uma sociedade solidária e amorosa, baseada na reciprocidade e alteridade com toda a criação. Irmã Dorothy, anjo da floresta, mártir da criação, continua a nos afetar! Despertadas/os por sua história de dor, sofrimento e morte, portanto, é que somos desafiadas/os a repensar nossa forma de cuidar das pessoas e da criação.

\section{Conclusão}

O conceito de cuidado compreendido como modo-de-ser, tal como nos inspirou Heidegger em sua compreensão da Sorge, é fundamental para se pensar o cuidado em sentido cristão. Em primeiro lugar, por que nos desinstala de nossos ambientes originalmente religiosos, já que não aquiesce a qualquer colonização do conceito. Ou seja, cuidar não é uma prerrogativa da religião, não se encerra no serviço pastoral de determinada denominação, não se constitui privilégio consequente de se pertencer a determinada hierarquia eclesiástica, nem se reduz à sua profissionalização. Nesse sentido, somos novamente convidados a um Cristianismo não religioso, tantas vezes reclamado por teólogos ao longo da história recente do Cristianismo, no contexto de qual ações humanas descaracterizadas de sua roupagem religiosa não sejam vistas como uma contraposição dualista do divino.

Em segundo lugar, Heidegger nos adverte que o cuidado não se reduz às ações ou intenções, o que significa que não deve ser compreendido como aquilo que temos, intentamos ou fazemos, mas, fundamentalmente, como aquilo que somos. Mais do que intentar o cuidado ou mesmo agir cuidadosamente, somos o próprio Cuidado. Essa personificação do cuidado nos aproxima de uma fé que se constrói em torno do evento da Encarnação, paradigma central do Cristianismo. A julgar pelo exemplo

${ }^{65}$ AGORA mais do que nunca: Irmã Dorothy Stang. 14 Fevereiro 2019. Disponível em: http://www.ihu.unisinos.br/78-noticias/586645-agora-mais-do-que-nunca-irmadorothy-stang. Acesso em 30 mar. 2019. 
de Cristo (Fp 2:6-11), o cuidado por excelência se constitui, portanto, numa disposição à comunhão dos sofrimentos, uma participação intensa e criativa num mundo não higienizado, onde a dor e o grito humano se fazem sentir. Dorothy Stang se fragilizou a ponto de se oferecer em sacrifício, não apenas às pessoas, mas, também, à terra que se tornou seu desafio e seu lar. Sua memória nos desinstala de nossos lugares de conforto, mas, ao mesmo tempo nos cura e nos convoca a continuarmos sua missão cuidadora. A mártir da floresta, Irmã Dorothy, é uma voz que deve ser reverberada, especialmente, neste tempo em que a Igreja católica se prepara para o Sínodo da Amazônia ${ }^{66}$, no qual se refletirá evangélica e profeticamente a crise e os povos da floresta, a biodiversidade e a terra.

\section{Referências}

AGORA mais do que nunca: Irmã Dorothy Stang. 14 Fevereiro 2019. Disponível em: http://www.ihu.unisinos.br/78-noticias/586645-agora-mais-do-que-nunca-irma-dorothy-stang. Acesso em 30 mar. 2019.

BACON, Francis. Novum Organum. In: EDITORA NOVA CULTURAL. Bacon. São Paulo, 1999.

BINGEMER, Maria Clara Lucchetti. Mulheres da história recente do Brasil: Dorothy Stang, 2009, p.1-3. Disponível em: http://agape.usuarios.rdc.puc-rio.br/amai/mulheresdahistoria1.doc. Acesso em 20 mar. 2019.

BINGEMER, Maria Clara. Teologia latino-americana: raízes e ramos. Rio de Janeiro: Vozes, 2017.

BOFF, Leonardo. Saber cuidar: ética do humano, compaixão pela terra. 12. ed. Petrópolis: Vozes, 1999.

BOFF, Leonardo. São Francisco de Assis: ternura e vigor. 9. Ed. Petrópolis: Vozes, 2002.

\footnotetext{
${ }^{66}$ O sínodo acontecerá nos dias 06 a 27 de outubro de 2019. DOCUMENTO Preparatório. Amazônia: Novos Caminhos para a Igreja e para uma Ecologia Integral. Disponível em: http://www.synod.va/content/synod/it/attualita/sinodo-da-amazonia-documento-preparatorio--amazonia--novos-cami.html. Acesso em 29 mar. 2019.
} 
DOCUMENTO Preparatório. Amazônia: Novos Caminhos para a Igreja e para uma Ecologia Integral. Disponível em: http://www.synod.va/ content/synod/it/attualita/sinodo-da-amazonia--documento-preparatorio--amazonia--novos-cami.html. Acesso em 29 mar. 2019.

GARCIA, Leoni Alves. Dorothy Stang e Ezequiel Ramim, testemunhas de uma vida doada pela Amazônia. 23 de julho de 2018. Disponível em: https://cebsdobrasil.com.br/2018/07/23/dorothy-stang-e-ezequiel -ramim-testemunhas-de-uma-vida-doada-pela-amazonia1/. Acesso em 27 mar. 2019.

GUZZO, Maria Rosário Souza; SANTANA, Nivalda Silva de. Irmã Dorothy Stang: a mártir dos PDS. A vida de Dorothy Stang na Amazônia. Anapu, 2009.

HABERMAS, Jürgen. Teoría de la acción comunicativa I: racionalidad de la acción y racionalización social. Madri: Taurus, 1987.

HEIDEGGER, Martin. Carta sobre el humanismo. Madrid: Alianza Editorial, 2006.

HEIDEGGER, Martin. Ser e tempo. 2. ed. Petrópolis: Vozes; Bragança Paulista: Editora Universitária São Francisco, 2007.

KANT, Emmanuel. Crítica da faculdade do juízo. 3. ed. Rio de Janeiro: Forense Universitária, 2012.

LALANDE, André. Vocabulário técnico e crítico da Filosofia. 3. ed. São Paulo: Martins Fontes, 1999.

LE BRETON, Binka . A Dádiva Maior: a vida e a morte corajosas da Irmã Dorothy Stang. Trad. Renato Rezende. São Paulo: Globo, 2008.

NOUWEN, Henri J. M. O sofrimento que cura. 3. ed. São Paulo: Paulinas, 2007.

REALE; Giovanni; ANTISERI, Dario. História da filosofia: do romantismo até nossos dias, v. 3. 6. ed. São Paulo: Paulus, 2003, v. 3, p. 585.

RICOEUR, Paul. A hermenêutica bíblica. Tradução de Paulo Meneses. Apresentação de François-Xavier Amherdt. São Paulo: Edições Loyola, 2006.

ROCHA, Abdruschin Schaeffer. Revelação e vulnerabilidade: caminhos para uma hermenêutica da revelação a partir da presença-ausência. Tese de Doutorado - Departamento de Teologia, Pontifícia Universidade Católica do Rio de Janeiro. Rio de Janeiro, 2015. 
SALVOLDI, Valentino. Primeira mártir da criação: Dorothy Stang. Trad. Jaime A. Classen. São Paulo: Paulinas, 2012.

VELHO, Gilberto. Observando o familiar. In: NUNES, Edson de Oliveira (Org.). A aventura sociológica: objetividade, paixão, improviso e método na pesquisa social. Rio de Janeiro: Zahar, 1978.

Submetido em: 10/04/2019

Aceito em: 22/05/2019 